\title{
Off-stoichiometric defect clustering in irradiated oxides
}

\author{
Sarah Khalii ${ }^{1}$, Todd Allen ${ }^{1}$, Anter EL-Azab ${ }^{2}$ \\ ${ }^{1}$ Materials Science and Engineering, University of Wisconsin-Madison, Madison, WI 53706 \\ ${ }^{2}$ School of Materials Engineering, Purdue University, West Lafayette, IN 49707
}

\begin{abstract}
A cluster dynamics model describing the formation of vacancy and interstitial clusters in irradiated oxides has been developed. The model, which tracks the composition of the oxide matrix and the defect clusters, was applied to the early stage formation of voids and dislocation loops in $\mathrm{UO}_{2}$, and the effects of irradiation temperature and dose rate on the evolution of their densities and composition was investigated. The results show that Frenkel defects dominate the nucleation process in irradiated $\mathrm{UO}_{2}$. The results also show that oxygen vacancies drive vacancy clustering while the migration energy of uranium vacancies is a rate-limiting factor for the nucleation and growth of voids. In a stoichiometric $\mathrm{UO}_{2}$ under irradiation, off-stoichiometric vacancy clusters exist with a higher concentration of hyperstoichiometric clusters. Similarly, off-stoichiometric interstitial clusters form with a higher concentration of hyperstoichiometric clusters. The $\mathrm{UO}_{2}$ matrix was found to be hyper-stoichiometric due to the accumulation of uranium vacancies.
\end{abstract}

Keywords: $\mathrm{UO}_{2}$, cluster dynamics, voids, dislocation loops

\section{Introduction}

Oxides are ubiquitous in nuclear power applications. Among these oxides is uranium dioxide, $\mathrm{UO}_{2}$, which is used as a nuclear fuel due to its adequate chemical, physical and thermal properties. As a nuclear fuel, $\mathrm{UO}_{2}$ withstands the extreme condition of high-temperature particle irradiation, which leads to microstructural changes due to the 5 production of point defects at concentrations higher than the thermal equilibrium values. The irradiation-induced point defects diffuse and interact among themselves to form extended defects such as voids and interstitial loops. In the presence of fission gases such as $\mathrm{Xe}$ and $\mathrm{Kr}$, voids turn into gas bubbles. With continued irradiation, voids/bubbles and dislocation loops grow to alter the microstructure of $\mathrm{UO}_{2}$ and impact its thermo-mechanical performance. It is important to resolve the kinetics of nucleation and growth of voids, bubbles and loops in order to explain the microstructural evolution and the property changes in $\mathrm{UO}_{2}$ in the reactor environment.

Many irradiation studies reported the formation of interstitial loops and voids in $\mathrm{UO}_{2}$, showing the dependence of the void and loop density and size distribution on the irradiation dose and temperature (He et al., 2013; Turnbull, 1971; Baker, 1977; Cornell et al., 1969; Cornell and Turnbull, 1971; Nogita and Une, 1994). Oxides of a similar perovskite crystal structure such as $\mathrm{CeO}_{2}$ were also irradiated as surrogates materials for $\mathrm{UO}_{2}$ (Jonnet, 2007; Ye,

15 2011). Although most oxides invariably show the formation of small voids and dislocation loops under irradiation at temperatures high enough to permit the diffusion of point defects, little is known about the kinetics of the defect clustering that leads to the nucleation and growth of voids and loops in oxides. A question that poses itself in the case of oxides is whether composition plays a role in the dynamics of defect clustering and whether the nucleating clusters possess the stoichiometry suggested by the chemical formula of the oxide itself. An answer to this question 20 is attempted here by cluster dynamics modeling.

Cluster dynamics has long been used to understand the early stages of nucleation and growth of vacancy and interstitial clusters in irradiated metals (Ghoniem and Gurol, 1981; Ning et al., 2012; Christien and Barbu, 2009; Gokhman and Bergner, 2009). The method is based on a set of rate equations that describe the evolution of the average densities of defects of different sizes, ranging from monomers (single vacancies and interstitials) to large 25 clusters. The evolution of these clusters is controlled by transitions involving absorption and emission of defects, i.e., by defects and cluster reactions, and it is driven by the production of defects by irradiation (Ghoniem and Sharafat, 
1980). Although most cluster dynamics formalisms ignore spatial dependences of the defects and cluster densities, it is often successful in describing reaction kinetics and time evolution of these densities over extended periods of time approaching the time scale of laboratory experiments. As far as oxides are concerned, only a limited number 30 of cluster dynamics studies was performed. From a modeling point of view, applying cluster dynamics to an oxide such as $\mathrm{UO}_{2}$ must account for the fact that such an oxide is a multi-component system. In studying the dynamics of vacancy and interstitial clusters in $\mathrm{UO}_{2}$, however, the assumption that defects also come in the form complexes with the same chemical formula as the parent oxide was previously made (Skorek et al., 2012; Jonnet, 2007; Ye, 2011). In $\mathrm{UO}_{2}$, this assumption meant that the basic vacancy unit is a complex consisting of a uranium vacancy and two oxygen

35 vacancies and basic interstitial unit consists of a uranium interstitial and two oxygen interstitials. Such complexes are assumed to diffuse and react as single units and, as a result, the nucleating clusters and the matrix are assumed to be stoichiometric at all times (Skorek et al., 2012; Jonnet, 2007; Ye, 2011).

The above assumption has some drawbacks. First of all, due to the differences in bonding and masses of various atoms in oxides, the defect production is always asymmetric. That is, one atom type, oxygen, is often displaced more 40 frequently than the metal atoms in oxide such as $\mathrm{UO}_{2}$ and $\mathrm{CeO}_{2}$ under particle irradiation (Matzke, 1987). The differences in point defect migration energies and binding energies to other lattice defects, makes it possible to have vacancy and interstitial clusters having compositions different from the stoichiometric oxide. Such clusters are called here off-stoichiometric clusters. When the population of off-stoichiometric clusters grow in the matrix, the matrix itself becomes off-stoichiometric even if the overall material is stoichiometric. Indeed, several studies confirmed the

45 tendency of $\mathrm{UO}_{2}$, for example, to oxidize, i.e., become hyper-stoichiometric by irradiation, which implies that defect clustering proceeds in a non-stoichiometric fashion (Hassan et al., 2013; Lyons et al., 1972; Gupta, 2015). Offstoichiometry consideration in defect clustering is thus critical for the interpretation of experimental observations of irradiated oxides.

A cluster dynamics model that accounts for off-stoichiometry of clusters and matrix was developed and applied 50 to investigate the clustering behavior of vacancies and interstitials and the formation of voids and dislocation loops in irradiated $\mathrm{UO}_{2}$. Implementation of the model requires a predetermination of the range of off-stoichiometric clusters that may be considered in the model. This requirement led to the creation of so-called the cluster composition space (CCS), outside of which no clusters are possible to exist. Within this space, the density evolution of clusters is studied in regard to both the size and composition of clusters. The model was applied to investigate the cluster density distribution and the dependence of the density on irradiation dose rate and temperature in $\mathrm{UO}_{2}$.

\section{Methodology}

\subsection{Overview}

A typical CD model consists of a coupled set of Ordinary Differential Equations (ODEs) governing the evolution of the density of clusters at all sizes. In the case of $\mathrm{UO}_{2}$, a vacancy or interstitial cluster is characterized by the number so and type of defects contained in the cluster. To fix ideas, the Kröger-Vink notation (Kröger and Vink, 1956) for such defects in introduced: the vacant oxygen and uranium lattice sites are denoted by $\mathrm{V}_{\mathrm{O}}$ and $\mathrm{V}_{\mathrm{U}}$, respectively, and the oxygen and uranium atoms on interstitial sites are denoted by $\mathrm{O}_{i}$ and $\mathrm{U}_{\mathrm{i}}$, respectively. These defects are assumed to be the fundamental defects produced by the irradiation damage process at a given rate determined by the irradiation dose rate. They are called monomers.

The cluster population is divided into two main classes, vacancy clusters (voids) and interstitial clusters (loops). Within each class, a cluster is characterized by its defect contents, $n$ uranium and $m$ oxygen point defects (monomers). The pair of numbers $(n, m)$ is thus used to denote both the cluster size and composition. For each value of $n, m$ is selected such that the cluster falls within the cluster composition space. A vacancy cluster (void), for example, that has a specific number, $n$, of uranium vacancies, $\mathrm{V}_{\mathrm{U}}$, may have $m$ oxygen vacancies, $\mathrm{V}_{\mathrm{O}}$, in the range $\left(m_{\min }, m_{\max }\right)$, with 70 the ratio $n / m=1 / 2$ falling between $m_{\min }$ and $m_{\max }$. Clusters with $n / m<1 / 2$ are called hyper-stoichiometric clusters, those with $n / m=1 / 2$ are called stoichiometric, and those with $n / m>1 / 2$ are called hypo-stoichiometric.

The cluster dynamics equations are a set of coupled nonlinear reaction equations for the evolution of the density of clusters of all sizes and compositions. These equations have the general form:

$$
\frac{\mathrm{d} C(n, m)}{\mathrm{d} t}=T_{\mathrm{f}}^{(n, m)}(\mathbf{C})-T_{\mathrm{r}}^{(n, m)}(\mathbf{C})+G(n, m)-R(n, m),
$$


where $C(n, m)$ is the concentration or density of clusters of size $(n, m), \mathbf{C}$ is the set of cluster concentrations, $T_{\mathrm{f}}^{(n, m)}(\cdot)$ is the transition operator for the processes leading to formation of clusters of size $(n, m), T_{\mathrm{r}}^{(n, m)}(\cdot)$ is the transition operator representing removal of clusters from this category, $G(n, m)$ is the direct production rate from the irradiation process, and $R(n, m)$ is the rate of removal of clusters from the system by reaction with sinks other than clusters. As a modeling assumption, the terms $G(n, m)$ and $R(n, m)$ are assumed to be non-trivial only for monomers whose concentrations are denoted by $C(1,0)$ and $C(0,1)$ for uranium and oxygen point defects, respectively. As shown in subsection 2.2, the first and second terms to the right-hand side involve products of cluster concentrations higher than monomers with the concentrations of the monomers themselves.

A robust numerical method must be used in order to solve the above set of coupled non-linear ordinary differential equations. Here, the Livermore Solver for Ordinary Differential Equations (LSODE) package (Hindmarsh, 1982) was used. This package solves stiff ODE systems based on the explicit predictor-corrector method with an automatic switch for stiff and non-stiff problems (Petzold, 1983). LSODE was applied to a test problem considered in (Ghoniem and Sharafat, 1980), involving vacancies and interstitials in pure iron. A constant density of network dislocation density of $1 \times 10^{-8} \mathrm{~cm} / \mathrm{cm}^{3}$ was assumed as the only sink present in the system. Vacancy clusters are treated as spherical voids with a thermal emission term that depends on the cluster size. Interstitial clusters are treated as spherical clusters for small size clusters and as planar loops for bigger clusters. Point defects are assumed to be the only mobile species. Results of this test, which are reported elsewhere (Khalil, 2014), show that the solver is effective in handling cluster dynamics equations of the type considered here.

Solving the cluster dynamics rate equations for $\mathrm{UO}_{2}$ requires defining the off-stoichiometry limits for clusters that can structurally exist. This amounts to finding the minimum, $m_{\min }$, and maximum, $m_{\max }$, number of oxygen monomers that can combine with a given number $n$ of uranium monomers. The process fo finding $m_{\min }$ and $m_{\max }$ for a prescribed $n$ fixes the boundaries of the cluster composition space. A search algorithm is designed to do so for the fluorite crystal structure of $\mathrm{UO}_{2}$

For vacancy clusters, the algorithm works as follows. Imagine that $n \mathrm{U}$ atoms are removed from the lattice to form $n \mathrm{~V}_{\mathrm{U}}$. Such vacancies may not be separated by other $\mathrm{U}$ atoms. The minimum and maximum numbers of $\mathrm{V}_{\mathrm{O}}$ envisioned to form a void with such $n \mathrm{~V}_{\mathrm{U}}$ then correspond to the cases where all $\mathrm{O}$ atoms are removed up to a shell outside and inside the removed $\mathrm{U}$ atoms, respectively. That is, a cluster containing $n \mathrm{~V}_{\mathrm{U}}$ can either be terminated with a $\mathrm{U}$ or $\mathrm{O}$ atoms, corresponding to $m_{\min }$ and $m_{\max }$, respectively. These values depend on the assumed cluster geometry, which is assumed here to be spheroidal. For values of $n$ up to 300, $m_{\min }$ and $m_{\max }$ were found and fit to equations defining the lower and upper boundaries of the vacancy cluster composition space. Figuring these limits upfront ensures that the number of cluster dynamics equations to be soved is the smallest possible, thus saving computational ime. Figure 1 shows the composition space for vacancy clusters (voids) of size $(n, m)$. For an $n$ number of uranium vacancies, the number $m$ of oxygen vacancies read from the blue, green, and red lines represent the $m_{\min }, m=2 n$, and $m_{\max }$, respectively. The green line represents stoichiometric clusters. No clusters are allowed to exist above the upper line or below the lower line.

In the current work, it is assumed that interstitial clusters have the same off-stoichiometric range as vacancy 110 clusters. This assumption has been checked by actual calculations of the interstitial cluster composition space. Frank loops with Burgers vector of $b=1 / 3<111>$ type are energetically more favorable than the perfect loops with with $b=1 / 2<001>$ (Miao et al., 2014). The interstitial loops are thus assumed to be mainly Frank loop type. A Frank loop in $\mathrm{UO}_{2}$ contains two $\mathrm{O}_{\mathrm{i}}$ layers with a $\mathrm{U}_{\mathrm{i}}$ layer in between. A stoichiometric loops contains the same number of atoms in the three layers. For a given number $n$ of $U_{i}$, and starting from the stoichiometric configuration of the loop, the minimum number of $\mathrm{O}_{\mathrm{i}}$ that can exist in the loop is found subtracting $\mathrm{O}_{\mathrm{i}}$ until a $\mathrm{U}_{\mathrm{i}}$ must be removed; similarly, the maximum number of $\mathrm{O}_{\mathrm{i}}$ can be found by adding $\mathrm{O}_{\mathrm{i}}$ until a $\mathrm{U}_{\mathrm{i}}$ must be added, again starting from the stoichiometric configuration.

\subsection{Cluster dynamics model details}

In developing the cluster dynamics model, it is assumed that irradiation causes cation and anion displacements in the oxide matrix, thus introducing $\mathrm{V}_{\mathrm{O}}, \mathrm{O}_{\mathrm{i}}, \mathrm{V}_{\mathrm{U}}$ and $\mathrm{U}_{\mathrm{i}}$ monomers into the system at a given rate. These defects come in the form Schottky and anti-Schottky defects (Martin et al., 2010) at equal rates. It is also assumed that the monomers diffuse in the matrix, and can mutually annihilate, disappear at sinks, or bind together to form clusters. Cluster dynamics does not consider gradients in space and, therefore, diffusion comes into the picture indirectly through the 


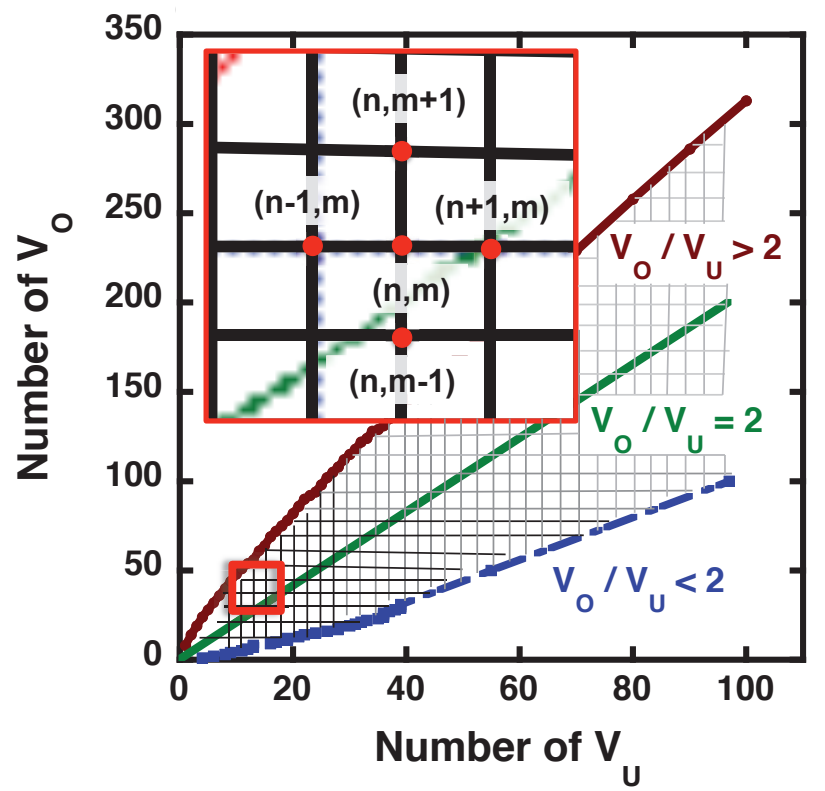

Figure 1: Composition space for vacancy clusters. The blue and brown lines represent the minimum and maximum numbers of oxygen vacancies that can exist in a cluster with a given number of uranium vacancies. The middle green line represents the 2:1 ratio of oxygen to uranium vacancies. The inset is an enlargment of the mesh points enclosed in the small square.

dependence of the reaction rates of monomers on the respective diffusion coefficients. The cluster dynamics problem can thus be stated as follows: given that monomers are introduced at a given rate, find the density evolution of clusters of all sizes and composition in a material with a given sink density. In the current case, only network dislocations are considered as sinks and the material is considered a large single crystal irradiated uniformly.

Two types of clusters are considered, vacancy clusters (small voids) and interstitial clusters (dislocation loops). The type of loops considered here is Frank loops with Burgers vector of the type $b=1 / 3<111>$, as opposed o the perfect dislocation loops with $b=1 / 2<001>$, which is consistent with the experimental and molecular dynamics studies Miao et al. (2014). These loops consist of three layers of atoms parallel to the (111) planes, the middle of which is a U layer. Voids are assumed to have spherical shapes shapes. In reality, large, well established voids have truncated octahedral shapes ( $\mathrm{Li}$ et al., 2012). Although loops may have shapes other than circular, e.g., hexagonal or any irregular shapes, they are assumed to be circular disks. These assumptions are justified by the fact that voids and loops considered here are small, $1 \mathrm{~nm}$ void radii and 3-4 nm loop radii. It is further assumed that voids and loops grow by absorbing vacancies and interstitials, respectively, and shrink by absorbing the anti-defects. Emission of vacancies from voids and interstitials from loops is also a mechanism of shrinkage of these features. Finally, it is assumed that only monomers are mobile and that the the dislocation loops are biased sinks, i.e., they absorb interstitials more than vacancies.

The voids and loops are assumed to have compositions described by the cluster space in figure 1, with densities denoted by $C_{\mathrm{V}}(n, m)$ amd $C_{\mathrm{L}}(n, m)$, respectively. These densities evolve according to the following equations:

$$
\begin{aligned}
\frac{\mathrm{d} C_{\mathrm{V}}(n, m)}{\mathrm{d} t}= & \beta_{\mathrm{V}}^{\mathrm{V}_{\mathrm{U}}}(n-1, m) C_{\mathrm{V}_{\mathrm{U}}} C_{\mathrm{V}}(n-1, m)+\beta_{\mathrm{V}}^{\mathrm{V}_{\mathrm{O}}}(n, m-1) C_{\mathrm{V}_{\mathrm{O}}} C_{\mathrm{V}}(n, m-1) \\
& +\left[\beta_{\mathrm{V}}^{\mathrm{U}_{\mathrm{i}}}(n+1, m) C_{\mathrm{U}_{\mathrm{i}}}+\alpha_{\mathrm{V}}^{\mathrm{V}_{\mathrm{U}}}(n+1, m)\right] C_{\mathrm{V}}(n+1, m) \\
& +\left[\beta_{\mathrm{V}}^{\mathrm{O}_{\mathrm{i}}}(n, m+1) C_{\mathrm{O}_{\mathrm{i}}}+\alpha_{\mathrm{V}}^{\mathrm{V}_{\mathrm{O}}}(n, m+1)\right] C_{\mathrm{V}}(n, m+1) \\
& -\left[\alpha_{\mathrm{V}}^{\mathrm{V}_{\mathrm{U}}}(n, m)+\beta_{\mathrm{V}}^{\mathrm{U}_{\mathrm{i}}}(n, m) C_{\mathrm{U}_{\mathrm{i}}}+\beta_{\mathrm{V}}^{\mathrm{V}_{\mathrm{U}}}(n, m) C_{\mathrm{V}_{\mathrm{U}}}\right] C_{\mathrm{V}}(n, m) \\
& -\left[\alpha_{\mathrm{V}}^{\mathrm{V}_{\mathrm{O}}}(n, m)+\beta_{\mathrm{V}}^{\mathrm{O}_{\mathrm{i}}}(n, m) C_{\mathrm{O}_{\mathrm{i}}}+\beta_{\mathrm{V}}^{\mathrm{V}_{\mathrm{O}}}(n, m) C_{\mathrm{V}_{\mathrm{O}}}\right] C_{\mathrm{V}}(n, m),
\end{aligned}
$$




$$
\begin{aligned}
\frac{\mathrm{d} C_{\mathrm{L}}(n, m)}{\mathrm{d} t}= & \beta_{\mathrm{L}}^{\mathrm{U}_{\mathrm{i}}}(n-1, m) C_{\mathrm{U}_{\mathrm{i}}} C_{\mathrm{L}}(n-1, m)+\beta_{\mathrm{L}}^{\mathrm{O}_{\mathrm{i}}}(n, m-1) C_{\mathrm{O}_{\mathrm{i}}} C_{\mathrm{L}}(n, m-1) \\
& +\left[\beta_{\mathrm{L}}^{\mathrm{V}_{\mathrm{U}}}(n+1, m) C_{\mathrm{V}_{\mathrm{U}}}+\alpha_{\mathrm{L}}^{\mathrm{U}_{\mathrm{i}}}(n+1, m)\right] C_{\mathrm{L}}(n+1, m) \\
& +\left[\beta_{\mathrm{L}}^{\mathrm{V}_{\mathrm{O}}}(n, m+1) C_{\mathrm{V}_{\mathrm{O}}}+\alpha_{\mathrm{L}}^{\mathrm{O}_{\mathrm{i}}}(n, m+1)\right] C_{\mathrm{L}}(n, m+1) \\
& -\left[\alpha_{\mathrm{L}}^{\mathrm{U}_{\mathrm{i}}}(n, m)+\beta_{\mathrm{L}}^{\mathrm{V}_{\mathrm{U}}}(n, m) C_{\mathrm{V}_{\mathrm{U}}}+\beta_{\mathrm{L}}^{\mathrm{U}_{\mathrm{i}}}(n, m) C_{\mathrm{U}_{\mathrm{i}}}\right] C_{\mathrm{L}}(n, m) \\
& -\left[\alpha_{\mathrm{L}}^{\mathrm{O}_{\mathrm{i}}}(n, m)+\beta_{\mathrm{L}}^{\mathrm{V}_{\mathrm{O}}}(n, m) C_{\mathrm{V}_{\mathrm{O}}}+\beta_{\mathrm{L}}^{\mathrm{O}_{\mathrm{i}}}(n, m) C_{\mathrm{O}_{\mathrm{i}}}\right] C_{\mathrm{L}}(n, m),
\end{aligned}
$$

where $\beta_{\mathrm{T}}^{\mathrm{M}}(p, q)$ is the rate coefficient for the absorption of monomers of type $\mathrm{M}$ by a cluster of type $\mathrm{T}$ and size $(p, q)$ and $\alpha_{\mathrm{T}}^{\mathrm{M}}(p, q)$ is the rate of emission of monomers of type $\mathrm{M}$ from a cluster of type $\mathrm{T}$ and size $(p, q)$. The clusters type $\mathrm{T}$ can be $\mathrm{V}$ (voids) and $\mathrm{L}$ (loops), and the monomers can be of types $\mathrm{U}_{\mathrm{i}}, \mathrm{V}_{\mathrm{U}}, \mathrm{O}_{\mathrm{i}}$ and $\mathrm{V}_{\mathrm{O}}$, with concentrations denoted by $C_{\mathrm{U}_{\mathrm{i}}}, C_{\mathrm{V}_{\mathrm{U}}}, C_{\mathrm{O}_{\mathrm{i}}}$ and $C_{\mathrm{V}_{\mathrm{O}}}$, respectively. The time rate of change of these concentrations are given by:

$$
\begin{aligned}
\frac{\mathrm{d} C_{\mathrm{U}_{\mathrm{i}}}}{\mathrm{d} t}= & G_{\mathrm{U}_{\mathrm{i}}}-R_{\mathrm{iv}}^{\mathrm{U}} C_{\mathrm{U}_{\mathrm{i}}} C_{\mathrm{V}_{\mathrm{U}}} \\
& -R_{\mathrm{ii}} C_{\mathrm{O}_{\mathrm{i}}} C_{\mathrm{U}_{\mathrm{i}}}+\alpha_{\mathrm{L}}^{\mathrm{U}_{\mathrm{i}}}(1,1) C_{\mathrm{L}}(1,1)+\beta_{\mathrm{L}}^{\mathrm{V}_{\mathrm{O}}}(1,1) C_{\mathrm{V}_{\mathrm{O}}} C_{\mathrm{L}}(1,1) \\
& -C_{\mathrm{U}_{\mathrm{i}}} \sum_{l(n, m)}\left(\beta_{\mathrm{L}}^{\mathrm{U}_{\mathrm{i}}}(l) C_{\mathrm{L}}(l)+\beta_{\mathrm{V}}^{\mathrm{U}_{\mathrm{i}}}(l) C_{\mathrm{V}}(l)\right)+\sum_{l(n, m)} \alpha_{\mathrm{L}}^{\mathrm{U}_{\mathrm{i}}}(l) C_{\mathrm{L}}(l), \\
\frac{\mathrm{d} C_{\mathrm{V}_{\mathrm{U}}}}{\mathrm{d} t}= & G_{\mathrm{V}_{\mathrm{U}}}-R_{\mathrm{iv}}^{\mathrm{U}} C_{\mathrm{U}_{\mathrm{i}}} C_{\mathrm{V}_{\mathrm{U}}} \\
& -R_{\mathrm{vV}} C_{\mathrm{V}_{\mathrm{U}}} C_{\mathrm{V}_{\mathrm{O}}}+\alpha_{\mathrm{V}}^{\mathrm{V}_{\mathrm{O}}}(1,1) C_{\mathrm{V}}(1,1)+\beta_{\mathrm{V}}^{\mathrm{O}_{\mathrm{i}}}(1,1) C_{\mathrm{O}_{\mathrm{i}}} C_{\mathrm{V}}(1,1) \\
& -C_{\mathrm{V}_{\mathrm{U}}} \sum_{l(n, m)}\left(\beta_{\mathrm{V}}^{\mathrm{V}_{\mathrm{U}}}(l) C_{V}(l)+\beta_{\mathrm{L}}^{\mathrm{V}_{\mathrm{U}}}(l) C_{L}(l)\right)+\sum_{l(n, m)} \alpha_{\mathrm{V}}^{\mathrm{V}_{\mathrm{U}}}(l) C_{\mathrm{V}}(l), \\
\frac{\mathrm{d} C_{\mathrm{O}_{\mathrm{i}}}}{\mathrm{d} t}= & G_{\mathrm{O}_{\mathrm{i}}}-R_{\mathrm{iv}}^{\mathrm{O}} C_{\mathrm{O}_{\mathrm{i}}} C_{\mathrm{V}_{\mathrm{O}}} \\
& -R_{\mathrm{ii}} C_{\mathrm{O}_{\mathrm{i}}} C_{\mathrm{U}_{\mathrm{i}}}+\alpha_{\mathrm{L}}^{\mathrm{O}_{\mathrm{i}}}(1,1) C_{\mathrm{L}}(1,1)+\beta_{\mathrm{L}}^{\mathrm{V}_{\mathrm{U}}}(1,1) C_{\mathrm{V}_{\mathrm{U}}} C_{\mathrm{L}}(1,1) \\
& -C_{\mathrm{O}_{\mathrm{i}}} \sum_{l(n, m)}\left(\beta_{\mathrm{L}}^{\mathrm{O}_{\mathrm{i}}}(l) C_{\mathrm{L}}(l)+\beta_{\mathrm{V}}^{\mathrm{O}_{\mathrm{i}}}(l) C_{\mathrm{V}}(l)\right)+\sum_{l(n, m)} \alpha_{\mathrm{L}}^{\mathrm{O}_{\mathrm{i}}}(l) C_{\mathrm{L}}(l),
\end{aligned}
$$

and

$$
\begin{aligned}
\frac{\mathrm{d} C_{\mathrm{V}_{\mathrm{o}}}}{\mathrm{d} t}= & G_{\mathrm{V}_{\mathrm{O}}}-R_{\mathrm{iv}}^{\mathrm{O}} C_{\mathrm{O}_{\mathrm{i}}} C_{\mathrm{V}_{\mathrm{o}}} \\
& -R_{\mathrm{vv}} C_{\mathrm{V}_{\mathrm{U}}} C_{\mathrm{V}_{\mathrm{O}}}+\alpha_{\mathrm{V}}^{\mathrm{V}_{\mathrm{O}}}(1,1) C_{\mathrm{V}}(1,1)+\beta_{\mathrm{V}}^{\mathrm{U}_{\mathrm{i}}}(1,1) C_{\mathrm{U}_{\mathrm{i}}} C_{\mathrm{V}}(1,1) \\
& -C_{\mathrm{V}_{\mathrm{o}}} \sum_{l(n, m)}\left(\beta_{\mathrm{V}}^{\mathrm{V}_{\mathrm{o}}}(l) C_{\mathrm{V}}(l)+\beta_{\mathrm{L}}^{\mathrm{V}_{\mathrm{o}}}(l) C_{\mathrm{L}}(l)\right)+\sum_{l(n, m)} \alpha_{\mathrm{V}}^{\mathrm{V}_{\mathrm{o}}}(l) C_{\mathrm{V}}(l) .
\end{aligned}
$$
tively; $R_{\mathrm{vv}}$ and $R_{\mathrm{ii}}$ are the reaction rate coefficients for pairs $\left(\mathrm{V}_{\mathrm{U}}, \mathrm{V}_{\mathrm{O}}\right)$ and $\left(\mathrm{U}_{\mathrm{i}}, \mathrm{O}_{\mathrm{i}}\right)$, respectively. These coefficients represent the lowest order values of the $\beta_{\mathrm{T}}^{\mathrm{M}}$ coefficients, i.e., they equal $\beta_{\mathrm{T}}^{\mathrm{M}}$ when the cluster absorbing the monomer thus represents a list of such clusters.

In order to solve the rate equations simultaneously, we transform the mesh of compositions shown in figure 1 to an array with pointers to mesh nodes. Every node in the mesh corresponds to a cluster of composition $(n, m)$. A cluster of size $(n, m)$ has four first neighbor sizes in the composition space, where it can grow or shrink into one of these neighboring cluster categories. For example, the cluster of size $(n, m)$ can grow into a cluster of the size $(n+1, m)$ upon absorbing a uranium defect or to $(n, m+1)$ upon absorbing an oxygen defect. Similarly, a cluster of size $(n, m)$ 5

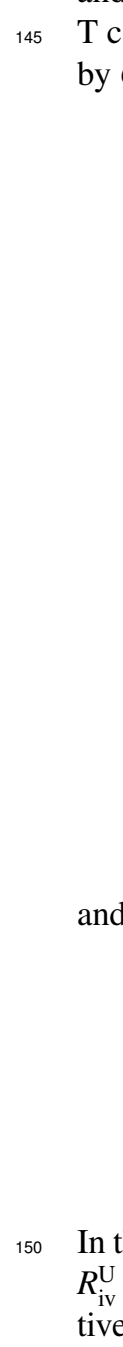

$R_{\text {iv }}^{\mathrm{U}}$

In the above equations, $G_{\mathrm{U}_{\mathrm{i}}}, G_{\mathrm{V}_{\mathrm{U}}}, G_{\mathrm{O}_{\mathrm{i}}}$ and $G_{\mathrm{V}_{\mathrm{O}}}$ are the generation rates for monomers $\mathrm{U}_{\mathrm{i}}, \mathrm{V}_{\mathrm{U}}, \mathrm{O}_{\mathrm{i}}$ and $\mathrm{V}_{\mathrm{O}}$, respectively;
$R_{\mathrm{iv}}^{\mathrm{U}}$ and $R_{\mathrm{iv}}^{\mathrm{O}}$ are the recombination rate coefficients for vacancies and interstitials on the $\mathrm{U}$ and $\mathrm{O}$ sublattices, respecof interest is a monomer of the other interstitial or vacancy species. The summations terms in the last four equations 
shrinks to one of size $(n-1, m)$ or $(n, m-1)$ by emitting a uranium defect or oxygen defect, respectively, or absorbing the anti-defect. The neighbor lists are prepared by the cluster dynamics code as a pre-processing calculation. This setup makes the number of terms in the rate equation of every cluster unique to the cluster. Upon form the cluster dynamics equations, LSODE package is applied to solve them.

\subsection{Model parameters and numerical simulations}

The rate coefficients occuring in the coupling terms of the cluster dynamics equations (2) through ( 7) depend on the size of the cluster and the energetics of the mobile defect interacting with them. The recombination coefficients of vacancies and interstitials on a sublattice $\mathrm{K}(\mathrm{K}$ stands for $\mathrm{U}$ and $\mathrm{O}$ ) are given by:

$$
\begin{aligned}
& R_{\mathrm{iv}}^{\mathrm{K}}=\frac{4 \pi \mathrm{r}_{\mathrm{iv}}^{\mathrm{K}}}{\Omega}\left(D_{\mathrm{K}_{\mathrm{i}}}(T)+D_{\mathrm{V}_{\mathrm{K}}}(T)\right), \\
& D_{\mathrm{K}_{\mathrm{i}}}(T)=D_{\mathrm{K}_{\mathrm{i}}}^{0} \exp \left(\frac{-E_{\mathrm{K}_{\mathrm{i}}}^{\mathrm{m}}}{k_{B} T}\right), \\
& D_{\mathrm{V}_{\mathrm{K}}}(T)=D_{\mathrm{V}_{\mathrm{K}}}^{0} \exp \left(\frac{-E_{\mathrm{V}_{\mathrm{K}}}^{\mathrm{m}}}{k_{B} T}\right),
\end{aligned}
$$

in which $\mathrm{r}_{\mathrm{iv}}^{\mathrm{K}}$ is the annihilation range of vacancies and interstitials on sublattice $\mathrm{K}, D_{\mathrm{V}_{\mathrm{K}}}(T)$ and $D_{\mathrm{K}_{\mathrm{i}}}(T)$ the diffusion coefficients of vacancies and interstitials on that sublattice, respectively, which have the usual Arrhenius expressions in terms of pre-exponential factors and migration energies, $E_{\mathrm{V}_{\mathrm{K}}}^{\mathrm{m}}$ and $E_{\mathrm{K}_{\mathrm{i}}}^{\mathrm{m}}$. in the above, $T$ is the absolute temperature and $k_{B}$ is Botlzmann's constant. The expressions for $R_{\mathrm{vv}}$ and $R_{\mathrm{ii}}$, which are the reaction rates of monomers of the same type, be it vacancy or interstitial, but different sublattices can be developed in the same fashion as $R_{\mathrm{iv}}^{\mathrm{K}}$ above. However, they are taken here as the limits of the $\beta_{\mathrm{T}}^{\mathrm{M}}(n, m)$ coefficients when the cluster itself is a monomer. For the case of a void, the latter coefficients are expressed in the form

$$
\begin{aligned}
& \beta_{\mathrm{V}}^{\mathrm{V}_{\mathrm{K}}}(n, m)=\frac{1}{\Omega}\left(\frac{4 \pi R_{\mathrm{V}}(n, m) D_{\mathrm{V}_{\mathrm{K}}}(T)}{1+\frac{a}{R_{\mathrm{V}}(n, m)}}\right), \\
& \beta_{\mathrm{V}}^{\mathrm{K}_{\mathrm{i}}}(n, m)=\frac{1}{\Omega}\left(\frac{4 \pi R_{\mathrm{V}}(n, m) D_{\mathrm{K}_{\mathrm{i}}}(T)}{1+\frac{a}{R_{\mathrm{V}}(n, m)}}\right),
\end{aligned}
$$

for the vacancy and interstitial absorption, respectively. Here Omega is the atomic volume, $a$ is the lattice parameter, and $R_{\mathrm{V}}(n, m)$ is the void radius. The latter is given by

$$
R_{\mathrm{V}}(n, m)=\left(\frac{3(n+m) \Omega}{4 \pi}\right)^{1 / 3}
$$

For the case of a loop, $\beta_{\mathrm{L}}^{\mathrm{M}}(n, m)$ are given by

$$
\begin{aligned}
& \beta_{\mathrm{L}}^{\mathrm{V}_{\mathrm{K}}}(n, m)=\frac{1}{\Omega}\left(\frac{4 \pi R_{\mathrm{L}}(n, m) Z_{\mathrm{L}}^{V_{K}} D_{\mathrm{V}_{\mathrm{K}}}(T)}{1+\frac{a}{R_{\mathrm{L}}(n, m)}}\right), \\
& \beta_{\mathrm{L}}^{\mathrm{K}_{\mathrm{i}}}(n, m)=\frac{1}{\Omega}\left(\frac{4 \pi R_{\mathrm{L}}(n, m) Z_{\mathrm{L}}^{K_{i}} D_{\mathrm{K}_{\mathrm{i}}}(T)}{1+\frac{a}{R_{\mathrm{L}}(n, m)}}\right),
\end{aligned}
$$

for the vacancy and interstitial absorption, respectively. Here $Z_{\mathrm{L}}^{\mathrm{V}_{\mathrm{K}}}$ and $Z_{\mathrm{L}}^{\mathrm{K}_{\mathrm{i}}}$ are bias factors defined in (Duparc et al., 2002) and $R_{\mathrm{L}}(n, m)$ is the loop radius given by

$$
R_{\mathrm{i}}(n, m)=\left(\frac{(n+m) \Omega}{\pi b}\right)^{1 / 2} .
$$

In the above $b$ is the Burgers vector of the loop. The rate coefficient of monomer emission from clusters is assumed to be trivial for voids and it is thus defined here for loops only. It is given as follows: 


$$
\begin{aligned}
& \alpha_{\mathrm{L}}^{\mathrm{V}_{\mathrm{K}}}(n, m)=\beta_{\mathrm{L}}^{\mathrm{V}_{\mathrm{K}}}(n, m) \exp \left(\frac{-E_{\mathrm{V}_{\mathrm{K}}}^{\mathrm{b}}(n, m)}{k_{B} T}\right), \\
& \alpha_{\mathrm{L}}^{\mathrm{K}_{\mathrm{i}}}(n, m)=\beta_{\mathrm{L}}^{\mathrm{K}_{\mathrm{i}}}(n, m) \exp \left(\frac{-E_{\mathrm{K}_{\mathrm{i}}}^{\mathrm{b}}(n, m)}{k_{B} T}\right),
\end{aligned}
$$

where $E_{\mathrm{V}_{\mathrm{K}}}^{\mathrm{b}}$ and $E_{\mathrm{K}_{\mathrm{i}}}^{\mathrm{b}}$ are the binding energies of vacancies and interstitials of type $\mathrm{K}(\mathrm{U}, \mathrm{O})$, respectively, to a dislocation loop of size $(n, m)$. These binding energies depend on the cluster size and are estimated according to the procedure explained in (Barbu and Clouet, 2007). For small clusters, $E_{\mathrm{V}_{\mathrm{K}}}^{\mathrm{b}}$ and $E_{\mathrm{K}_{\mathrm{i}}}^{\mathrm{b}}$ must be calculated using atomic scale models; values from the literature (Deforest, 1991) were thus used. For large clusters, $E_{\mathrm{V}_{\mathrm{K}}}^{\mathrm{b}}$ and $E_{\mathrm{K}_{\mathrm{i}}}^{\mathrm{b}}$ are extrapolated using the following expressions (Duparc et al., 2002):

$$
\begin{array}{r}
E_{\mathrm{V}_{\mathrm{K}}}^{\mathrm{b}}(l)=E_{\mathrm{V}_{\mathrm{K}}}^{\mathrm{f}}+\frac{E_{2 \mathrm{~V}_{\mathrm{K}}}^{\mathrm{b}}-E_{\mathrm{V}_{\mathrm{K}}}^{\mathrm{f}}}{2^{2 / 3}-1}\left[l^{2 / 3}-(l-1)^{2 / 3}\right], \\
E_{\mathrm{K}_{\mathrm{i}}}^{\mathrm{b}}(l)=E_{\mathrm{K}_{\mathrm{i}}}^{\mathrm{f}}+\frac{E_{2 \mathrm{~K}_{\mathrm{i}}}^{\mathrm{b}}-E_{\mathrm{K}_{\mathrm{i}}}^{\mathrm{f}}}{2^{2 / 3}-1}\left[l^{2 / 3}-(l-1)^{2 / 3}\right],
\end{array}
$$

where $l=l(n, m)=n+m, E_{\mathrm{V}_{\mathrm{K}}}^{\mathrm{f}}$ and $E_{\mathrm{K}_{\mathrm{i}}}^{\mathrm{f}}$ are the formation energies of the respective monomers, $E_{2 \mathrm{~V}_{\mathrm{K}}}^{\mathrm{b}}$ and $E_{2 \mathrm{~K}_{\mathrm{i}}}^{\mathrm{b}}$ are the binding energies of the respective dimers. The recombination radius for vacancies and interstitials, $r_{\mathrm{iv}}^{\mathrm{K}}$ is taken to be 2.5a. Table 1 contains values of parameters used in cluster dynamics simulation of defects in $\mathrm{UO}_{2}$ clusters. The values for the diffusion coefficients, migration energies, formation energies and binding energies are adopted from (Deforest, 1991; et al., 2013; Iwasawa et al., 2006; Yun et al., 2009), respectively. The production rate of the fuel is calculated as $5 \times 10^{5} \Omega \dot{\mathrm{F}}$ displacement per second (dpa/s) assuming uniform flux within the fuel, where $\Omega$ is the atomic volume of $\mathrm{UO}_{2}$ and $\dot{\mathrm{F}}$ is the fission rate density. LSODE package (Hindmarsh, 1982) is used to solve $\mathrm{CD}$ equations for the $\mathrm{UO}_{2}$

\begin{tabular}{|c|c|c|c|c|c|c|c|c|c|c|c|c|c|c|c|}
\hline Parameter & $\mathrm{D}_{\mathrm{V}_{\mathrm{U}}}^{0}$ & $\mathrm{D}_{\mathrm{v}_{\mathrm{O}}}^{0}$ & $\mathrm{D}_{\mathrm{U}_{\mathrm{i}}}^{0}$ & $\mathrm{D}_{\mathrm{O}_{\mathrm{i}}}^{0}$ & $\mathrm{E}_{\mathrm{O}_{\mathrm{i}}}^{\mathrm{m}}$ & $\mathrm{E}_{\mathrm{U}_{\mathrm{i}}}^{\mathrm{m}}$ & $\mathrm{E}_{\mathrm{v}_{\mathrm{O}}}^{\mathrm{m}}$ & $\mathrm{E}_{\mathrm{v}_{\mathrm{U}}}^{\mathrm{m}}$ & $\mathrm{E}_{\mathrm{O}_{\mathrm{i}}}^{\mathrm{f}}$ & $E_{U_{i}}^{f}$ & $E_{V_{U}}^{f}$ & $\mathrm{E}_{\mathrm{v}_{\mathrm{O}}}^{\mathrm{f}}$ & $\mathrm{E}_{\mathrm{V}_{\mathrm{OU}}}^{\mathrm{b}}$ & $\mathrm{E}_{\mathrm{OU}_{\mathrm{i}}}^{\mathrm{b}}$ & $\mathrm{a}$ \\
\hline Value & $\begin{array}{l}0.65 \\
\mathrm{~cm}^{2} / \mathrm{s}\end{array}$ & $\begin{array}{l}0.25 \\
\mathrm{~cm}^{2} / \mathrm{s}\end{array}$ & $\begin{array}{l}0.01 \\
\mathrm{~cm}^{2} / \mathrm{s}\end{array}$ & $\begin{array}{l}0.01 \\
\mathrm{~cm}^{2} / \mathrm{s}\end{array}$ & $\begin{array}{l}1.56 \\
\mathrm{eV}\end{array}$ & $\begin{array}{l}1.78 \\
\mathrm{eV}\end{array}$ & $\begin{array}{l}0.3 \\
\mathrm{eV}\end{array}$ & $\begin{array}{l}2.4 \\
\mathrm{eV}\end{array}$ & $\begin{array}{l}-0.44 \\
\mathrm{eV}\end{array}$ & $\begin{array}{l}4.7 \\
\mathrm{eV}\end{array}$ & $\begin{array}{l}8.45 \\
\mathrm{eV}\end{array}$ & $\begin{array}{l}4.46 \\
\mathrm{eV}\end{array}$ & $\begin{array}{l}2.2 \\
\mathrm{eV}\end{array}$ & $\begin{array}{l}3.13 \\
\mathrm{eV}\end{array}$ & $\begin{array}{l}5.468 \\
\AA\end{array}$ \\
\hline
\end{tabular}
model. The LSODE package has been used to solve CD equations model microstructure evolution in irradiated metals and alloys (Ning et al., 2012; Gokhman and Bergner, 2009; Duparc et al., 2002; Xu et al., 2007; Li et al., 2012).

Table1: Values of parameters used in the cluster dynamics model.

\section{Results and Discussion}

The sensitivity of the model results to the rate coefficients that couple the cluster dynamics equations is discussed first, followed by an analysis of the dependence of the clustering kinetics on the temperature and dose rate. As the rate coefficients depend on the diffusion coefficients of the mobile species and the size of clusters, the sensitivity analysis in regard to the rate coefficients boils down to investigating the dependence of cluster formation on the migration energy of the mobile monomers, $\mathrm{V}_{\mathrm{O}}, \mathrm{O}_{\mathrm{i}}, \mathrm{V}_{\mathrm{U}}$ and $\mathrm{U}_{\mathrm{i}}$. As shown below, in reporting the dependence of void number density and the average void size on the migration energies of the monomers, $E_{\mathrm{V}_{U}}^{m}$ was found to be most critical. The evolution of the stoichiometry of clusters and oxide matrix is analyzed at the end of this section.

Figure 2 displays the void density and average void size as a function of uranium vacancy migration energy. The simulation is carried out at $800{ }^{\circ} \mathrm{C}$ and irradiation dose rate of $9.2 \times 10^{-4} \mathrm{dpa} / \mathrm{s}$ up to $10^{4} \mathrm{~s}$. The figure shows a strong dependence on the migration energy of uranium vacancies. The slow migration of $\mathrm{V}_{\mathrm{U}}$ leads to an increased rate of nucleation and higher void density with lower average void size. It also leads to a decrease in the rate of vacancy-interstitial recombination. Although voids can grow faster by absorbing oxygen vacancies, this process itself is slowed down by the fact that uranium vacancies must also be absorbed by vacancy clusters to form voids. This scenario is illustrated in figure 3 , which shows color map snapshots of the concentration of vacancy clusters over the cluster composition space described in figure 1 . The dotted line in figure 3 represents clusters with stoichiometric 
composition, $m / n=2$. Clusters above the dotted line are hyper-stoichiometric and those below the dotted line are hypo-stoichiometric. In figure 3, the growth of vacancy clusters favors hyper-stoichiometric compositions, which means that a cluster absorbs more oxygen vacancies before it starts to absorb uranium vacancies. This is due to the fast migration of oxygen vacancies; compare the migration energies $\mathrm{E}_{\mathrm{V}_{\mathrm{O}}}^{\mathrm{m}}=0.3 \mathrm{eV}$ and $\mathrm{E}_{\mathrm{V}_{\mathrm{U}}}^{\mathrm{m}}=2.4 \mathrm{eV}$. Similar color maps for the evolution of the loop density under the same conditions are displayed in figure 4. Again the loop (interstitial cluster) growth initially favors off-stoichiometric compositions. While it is hard to distinguish the offstoichiometric growth trend from these figures, a quantitative analysis of the stoichiometry of the entire void and loop ensembles will follow.

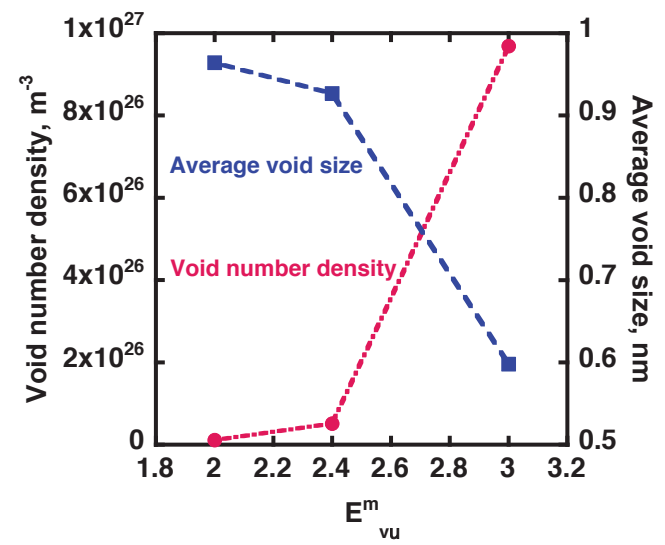

Figure 2: Dependence of the void density and the average void size on the migration energy of uranium vacancy. The simulation was carried out at $800^{\circ} \mathrm{C}$ and dose rate of $9.2 \times 10^{-4} \mathrm{dpa} / \mathrm{s}$ for $10^{4} \mathrm{~s}$.

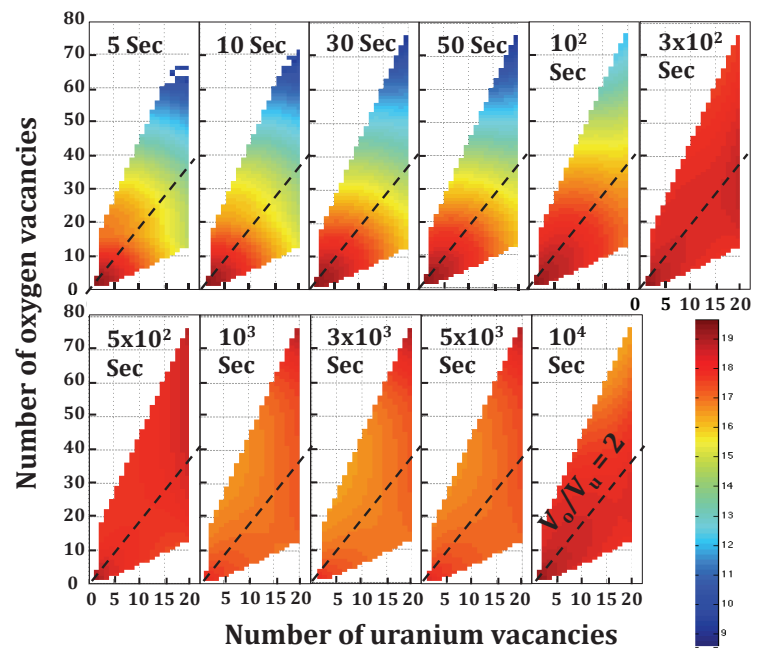

Figure 3: Time evolution of the vacancy cluster density at $800^{\circ} \mathrm{C}$ and $9.2 \times 10^{-4} \mathrm{dpa} / \mathrm{s}$. The horizontal and vertical axis labels refer to the numbers of $\mathrm{U}$ and $\mathrm{O}$ defects in the cluster, $n$ and $m$. The blue and red represent the lowest and highers density values.

Cluster dynamics simulations of the evolution of loops and voids in $\mathrm{UO}_{2}$ are carried out at temperatures in the range $500-1000^{\circ} \mathrm{C}$ and for the dose rates of $1 \times 10^{-5}$ and $5 \times 10^{-5}$. All simulations are run for $10^{4}$ seconds, which is comparable to time scale of some ion irradiation experiments. It is assumed that irradiation produces oxygen defects twice as much as uranium defects. Voids and loops are divided into three groups according to their composition: hyper-stoichiometric, $m / n>2$, stoichiometric, $m / n=2$, and hypo-stoichiometric, $m / n<2$.

Figure 5 shows the time evolution of the voids number density (a) and the loops number density (b) at $600{ }^{\circ} \mathrm{C}$ and 


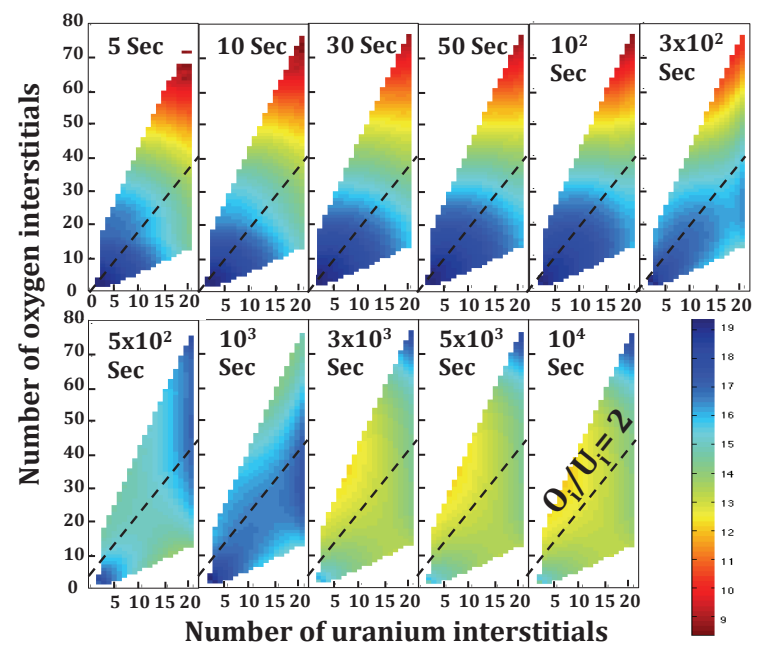

Figure 4: Time evolution of the concentration of interstitial clusters density at $800^{\circ} \mathrm{C}$ and $9.2 \times 10^{-4} \mathrm{dpa} / \mathrm{s}$. The horizontal and vertical axis labels refer to the numbers of $\mathrm{U}$ and $\mathrm{O}$ defects in the cluster, $n$ and $m$.The red and blue represent the lowest and highers density values.

$1 \times 10^{-5} \mathrm{dpa} / \mathrm{s}$. Th density of voids and loops with hypo-stoichiometric compositions, $m / n<2$, dominate at all times. (A hyper(hypo)-stoichiometric void contains more (less) oxygen vacancies than twice its uranium vacancy content, and a hyper(hypo)-stoichiometric loop contains more (less) oxygen interstitials than twice its uranium interstitial content.) At about $1000 \mathrm{~s}$, the density of voids and loops with stoichiometric compositions start to decrease while those with hyper-stoichiometric compositions start to increase. To investigate the temperature effect on the concentration of clusters, data in figure 5 at $600{ }^{\circ} \mathrm{C}$ are compared with data in figure 6 at $900{ }^{\circ} \mathrm{C}$ for the same dose rate. In the latter, hypo-stoichiometric composition for both voids and loops is initially favored till about $2000 \mathrm{~s}$ after which growth of voids and loops favors hyper-stoichiometric compositions. Simulation at $900{ }^{\circ} \mathrm{C}$ clearly show that, after a short initial stage, the density of clusters with hyper-stoichiometric compositions increases at the expense of hypoand stoichiometric clusters. The simulation also shows that voids and loops of stoichiometric compositions have the least concentration at all times after 2 secs from the onset of irradiation. Its is clear that majority of clusters have an non-stoichiometric composition, and the assumption that clusters are stoichiometric used in previous works (Skorek et al., 2012; Jonnet, 2007; Ye, 2011) thus lacks justification.
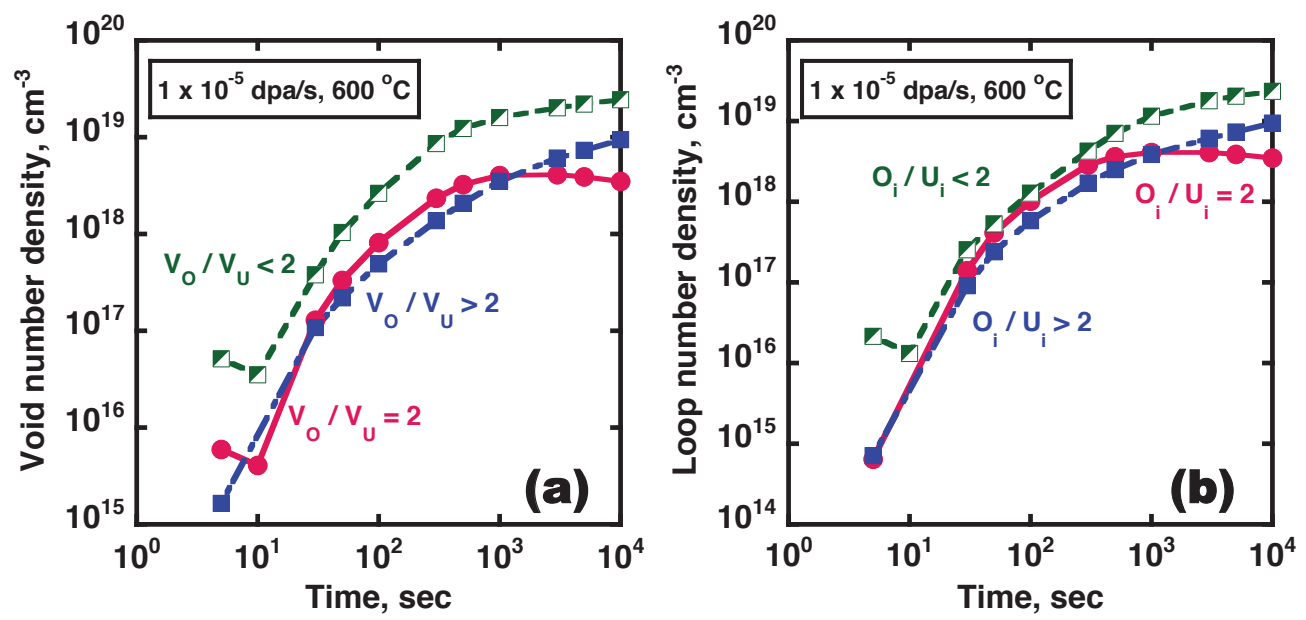

Figure 5: Time evolution of the density of stoichiometric and off-stoichiometric voids (a) and loops (b) at $600{ }^{\circ} \mathrm{C}$ and $1 \times 10^{-5}$ dpa/s. The ratio $m / n$ is repalced with the appropriate type of defects for clarity for clarity. For example, $\mathrm{V}_{\mathrm{O}} / \mathrm{V}_{\mathrm{U}}=2$ refers to a stoichiometric void with $m / n=2$. 

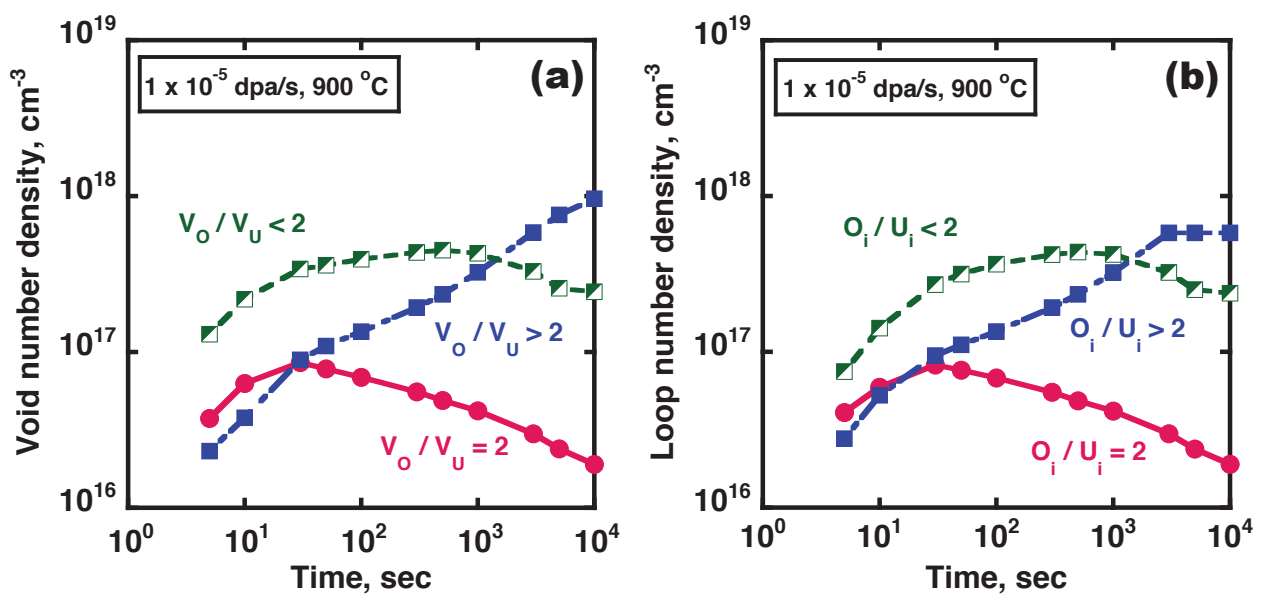

Figure 6: Time evolution of the density of stoichiometric and off-stoichiometric voids (a) and loops (b) at $900{ }^{\circ} \mathrm{C}$ and $1 \times 10^{-5}$ dpa/s. The ratio $m / n$ is repalced with the appropriate type of defects for clarity. For example, $\mathrm{V}_{\mathrm{O}} / \mathrm{V}_{\mathrm{U}}=2$ refers to a stoichiometric void with $m / n=2$

Vacancy clusters tend to absorb more of $\mathrm{V}_{\mathrm{O}}$, due to the high mobility of oxygen vacancies and the same can be said about interstitial clusters where the mobility of oxygen interstitial is relatively higher. As temperature increases the total void and loop densities decrease as a result of the decrease of nucleation rates due to increased defect mobility. As temperature increases hyper-stoichiometric voids (and loops) start to dominate sooner due to the increase in the mobility of oxygen defects.

Figure 7 shows the evolution of the average void size (a) and the average loop size (b) as a function of temperature $\left(500^{\circ} \mathrm{C}-1000{ }^{\circ} \mathrm{C}\right)$ and at a dose rate of $1 \times 10^{-5} \mathrm{dpa} / \mathrm{s}$. It is observed that as the temperature increases the average void and loop size increases due to the increased mobility of defects. This increase in average void or loops size with temperature is consistent with the decrease of the corresponding densities with temperature rise. At temperatures $\geq 800{ }^{\circ} \mathrm{C}$, the rate of increase of cluster size is higher due to mobility of uranium defects. To understand the effect of the dose rate, data plotted in figure 6 obtained at $900{ }^{\circ} \mathrm{C}$ and $1 \times 10^{-5} \mathrm{dpa} / \mathrm{s}$ are compared with figure 8 .
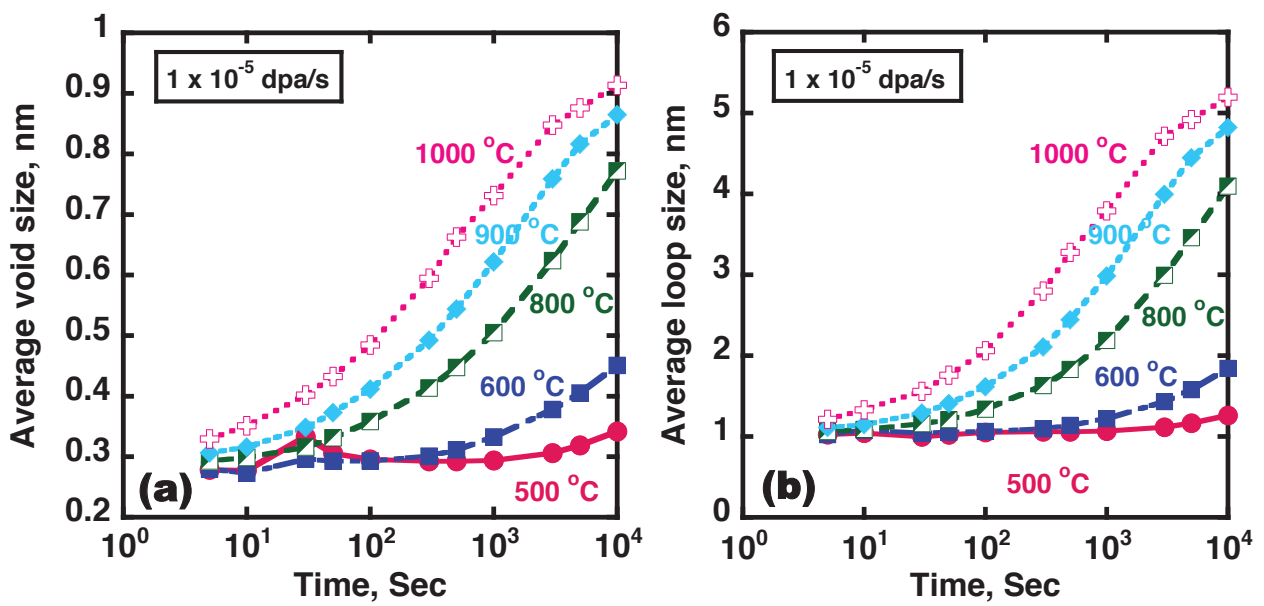

Figure 7: Time evolution of the average size of voids (a) and loops (b) as a function of temperature at $1 \times 10^{-5} \mathrm{dpa} / \mathrm{s}$.

Figure 8 shows the time evolution of the void (a) and the loop (b) densities at $900{ }^{\circ} \mathrm{C}$ and $5 \times 10^{-5} \mathrm{dpa} / \mathrm{s}$. It is found that the number density of clusters is generally higher at higher dose rate, and that clusters with hyper-stoichiometric composition dominate at an earlier time than at $1 \times 10^{-5} \mathrm{dpa} / \mathrm{s}$. A higher dose rate implies a higher defect production rate, which increase the number of nucleation sites and, in turn, the number density of vacancy and interstitial clusters. 
The increase in the concentration of oxygen defects leads to increase in the rate of formation of hyper-stoichiometric clusters.
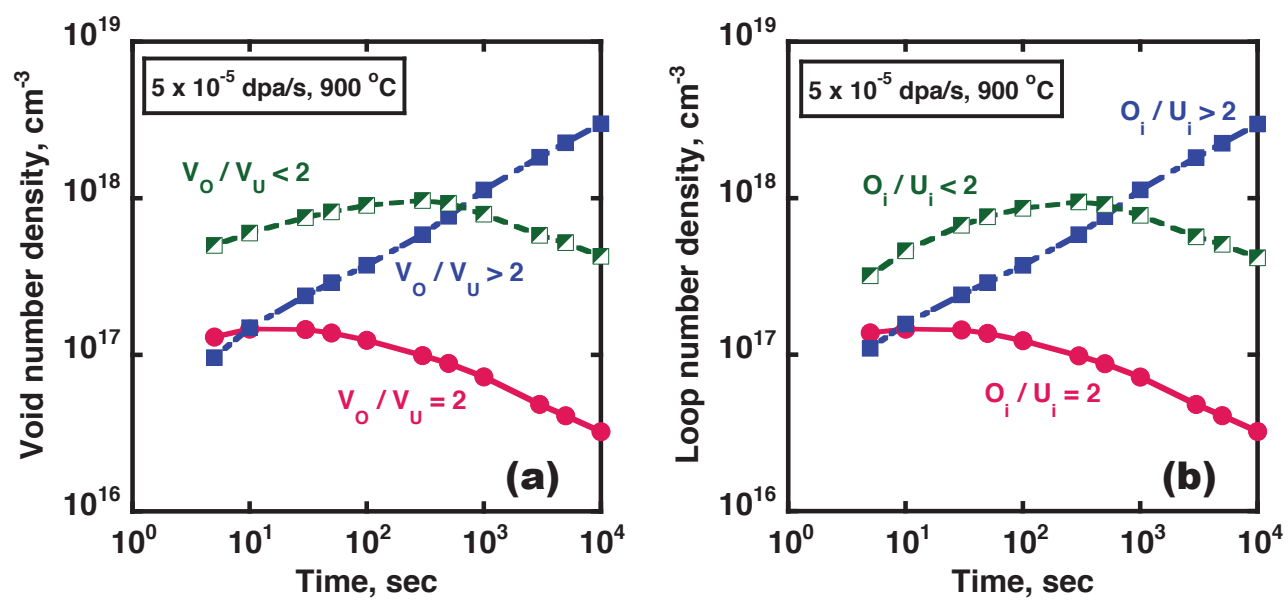

Figure 8: Time evolution of the number density of stoichiometric and off-stoichiometric compositions of (a) voids and (b) loops at $900{ }^{\circ} \mathrm{C}$ and $5 \times 10^{-5} \mathrm{dpa} / \mathrm{s}$.

The stoichiometry of the clusters and the matrix is discussed next. In figure 9, the evolution of average stoichiometry of (a) voids and (b) loops is determined as a function of temperature at $1 \times 10^{-5} \mathrm{dpa} / \mathrm{s}$. Average stoichiometry is defined as the ratio of $\mathrm{O}$ defects to $\mathrm{U}$ defects contained in the entire cluster ensemble, $\sum m / \sum n$, taken separately for voids and loops. For clarity, the ratios $\sum m / \sum n$ is replaced with $\left(\mathrm{V}_{\mathrm{O}} / \mathrm{V}_{\mathrm{U}}\right)_{\text {Voids }}$ for voids and by $\left(\mathrm{O}_{\mathrm{i}} / \mathrm{U}_{\mathrm{i}}\right)_{\mathrm{Loops}}$ for loops, respectively. The solid horizontal line represents the stoichiometric composition. The parts of the curves falling above this horizontal line indicate hyper-stoichiometry of clusters on average and vice versa. At $500{ }^{\circ} \mathrm{C}$ and $600{ }^{\circ} \mathrm{C}$, the ratios $\left(\mathrm{V}_{\mathrm{O}} / \mathrm{V}_{\mathrm{U}}\right)_{\text {Voids }}$ and $\left(\mathrm{O}_{\mathrm{i}} / \mathrm{U}_{\mathrm{i}}\right)_{\text {Loops }}$ are less than two, indicating average cluster hypo-stoichiometry at all times. However, at temperatures $\geq 800^{\circ} \mathrm{C}$, these ratios increase as a function of time to cross the stoichiometry line indicating a switch to hyper-stoichiometry of average cluster. The change in behavior from $600{ }^{\circ} \mathrm{C}$ to $800{ }^{\circ} \mathrm{C}$ is attributed to the enhancement of mobility of uranium defects at higher temperatures. The rate at which the composition of clusters transitions from hypo-stoichiometric to hyper-stoichiometric depends on temperature. The higher the temperature the sooner the average void and loop favors hyper-stoichiometry.
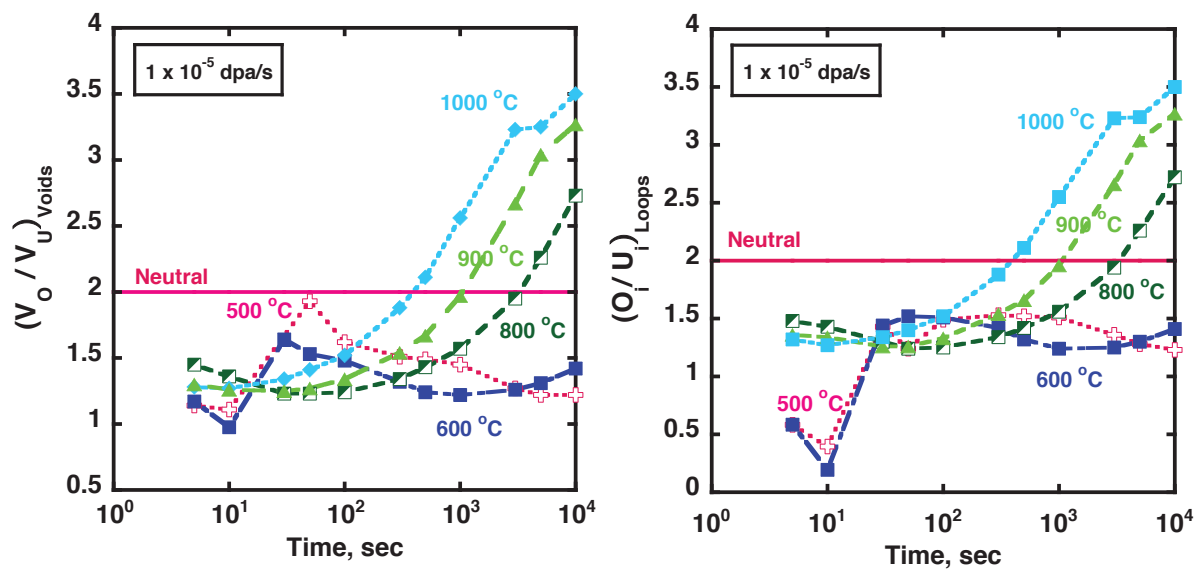

Figure 9: Time evolution of average non-stoichiometry, $\sum m / \sum n$, of (a) voids and (b) loops as a function of temperature at $1 \times 10^{-5}$ dpa/s. For clairty, the ratio is denoted by $\left(\mathrm{V}_{\mathrm{O}} / \mathrm{V}_{\mathrm{U}}\right)_{\text {Voids }}$ for voids and by $\left(\mathrm{O}_{\mathrm{i}} / \mathrm{U}_{\mathrm{i}}\right)_{\text {Loops }}$ for loops on the vertical axes. 
To investigate the corresponding changes in matrix, the density of monomers is tracked and analyzed. The concentrations of monomers are plotted in figure 10 at (a) $600{ }^{\circ} \mathrm{C}$ and (b) $900{ }^{\circ} \mathrm{C}$. As the figure indicates, the concentration of $\mathrm{O}_{\mathrm{i}}$ is about 5 orders of magnitude higher than $\mathrm{V}_{\mathrm{O}}$ at all times at both temperatures. At $600{ }^{\circ} \mathrm{C}$ and after few seconds, the concentration of $\mathrm{V}_{\mathrm{U}}$ increases and the concentration of $\mathrm{U}_{\mathrm{i}}$ decreases rapidly such that the difference is about three and two orders of magnitudes at $600{ }^{\circ} \mathrm{C}$ and $900^{\circ} \mathrm{C}$, respectively. The dominance of $\mathrm{O}_{\mathrm{i}}$ over $\mathrm{V}_{\mathrm{O}}$ and $\mathrm{V}_{\mathrm{U}}$ over $\mathrm{U}_{\mathrm{i}}$ indicates that the matrix is oxidized by irradiation after few seconds. However, since the concentration of $\mathrm{V}_{\mathrm{U}}$ is orders of magnitude higher than the concentration of $\mathrm{O}_{\mathrm{i}}$ at $900{ }^{\circ} \mathrm{C}$, then the oxidation effect of the matrix is due to the accumulation of $\mathrm{V}_{\mathrm{U}}$. This is a significant result that agrees with a significant body of literature indicating the tendency of $\mathrm{UO}_{2}$ to oxidize, i.e., become hyper-stoichiometric, by irradiation. Hyper-stoichiometry of $\mathrm{UO}_{2}$ was previously found to be due to accumulation of $\mathrm{V}_{\mathrm{U}}$ rather than $\mathrm{O}_{\mathrm{i}}$ by equilibrium thermodynamic calculations (Hassan et al., 2013).
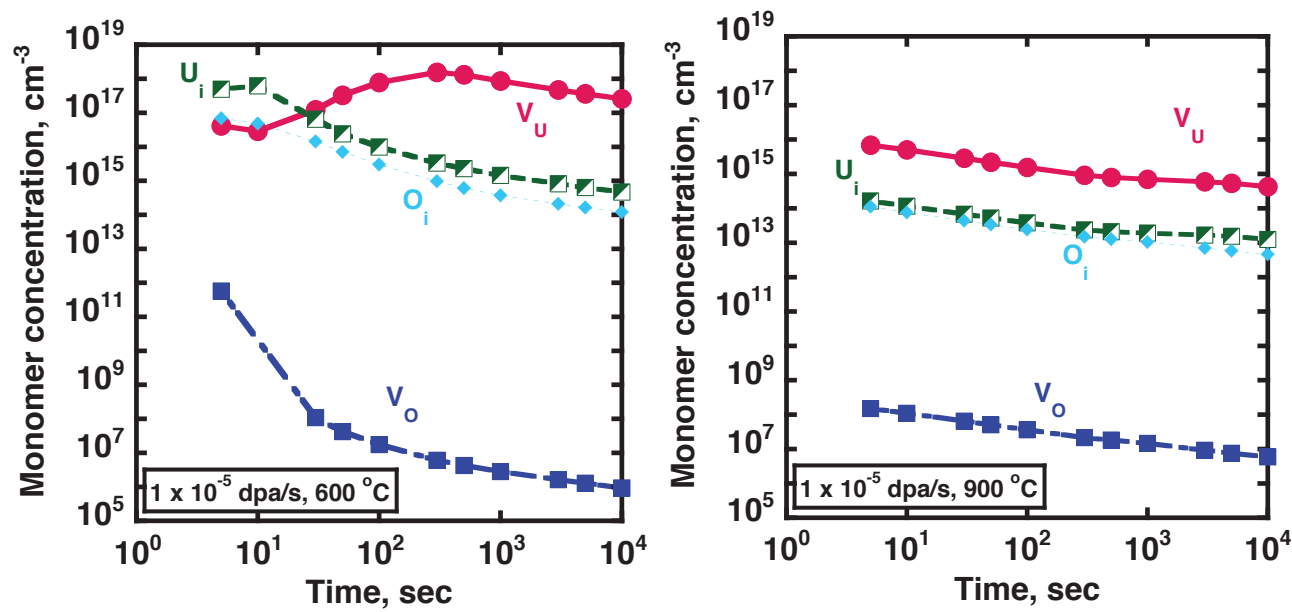

Figure 10: Evolution of the concentrations of monomers at $1 \times 10^{-5} \mathrm{dpa} / \mathrm{s}$ and temperatures of (a) $600{ }^{\circ} \mathrm{C}$ and (b) $900{ }^{\circ} \mathrm{C}$.

In figure 11, the ratios $\left(\mathrm{O}_{\mathrm{i}} / \mathrm{U}_{\mathrm{i}}\right)_{\text {Matrix }}$ and $\left(\mathrm{V}_{\mathrm{O}} / \mathrm{V}_{\mathrm{U}}\right)_{\text {Matrix }}$ are plotted as a function of time at temperatures $600{ }^{\circ} \mathrm{C}$ and $900{ }^{\circ} \mathrm{C}$ and a dose rate of $1 \times 10^{-5} \mathrm{dpa} / \mathrm{s}$. The ratios are less than 2 at both temperatures at all times due to the high concentrations of $\mathrm{U}_{\mathrm{i}}$ and $\mathrm{V}_{\mathrm{U}}$. This is a result of the low mobility of uranium defects as compared to oxygen defects. The non-stoichiometry of the matrix is expressed as $\mathrm{U}_{1+\mathrm{x}} \mathrm{O}_{2}$ at temperatures above $600{ }^{\circ} \mathrm{C}$, where $x$ is a negative parameter. In figure 11 (c), the stoichiometric parameter $x$ calculated as $x=\left(\mathrm{C}_{\mathrm{U}_{\mathrm{i}}}-\mathrm{C}_{\mathrm{V}_{\mathrm{U}}}\right) / \mathrm{N}$, where $N$ is the molecular density of $\mathrm{UO}_{2}$, is plotted as function of time at $600{ }^{\circ} \mathrm{C}$ and $900{ }^{\circ} \mathrm{C}$. Similar to the observation from figure 10 , at $600{ }^{\circ} \mathrm{C}$ the matrix is hypo-stoichiometric until a few seconds ( $x$ positive), then it becomes hyper-stoichiometric ( $x$ negative). At $900{ }^{\circ} \mathrm{C}$, the matrix is hyper-stoichiometric at all times with a decreasing value of $x$ due to the decrease in the concentration of $\mathrm{V}_{\mathrm{U}}$ as their mobility increases with temperature.

Taking into consideration off-stoichiometry of clusters, the model presented here gave insight into the the behavior of multicomponent systems in a number of ways. For example, it made it possible to extract the density evolution of voids and loops, not just in terms of sizes but also in terms of composition. This enables us to understand the state of the matrix itself and reach a better understanding of microscopy data collected on irradiated oxides. In addition, a detailed account and sensitivity analysis of the dependence of model results on defect energetics, formation, binding and migration energies, makes it possible to determine the rate limiting process. For example, it has been shown that the migration energies of $U$ defects represent the rate limiting factors in cluster density evolution. In fact, the limited ability of $U$ vacancies to diffuse also proved to be a reason $U$ vacancies accumulate in the matrix leading to its tendency to be hyper-stoichiometric upon irradiation. One further important aspect of the current model is its ability to obtain a detailed picture of defect clusters on the order of $1 \mathrm{~nm}$ or below. Such clusters, which seem to be present at high density in irradiated $\mathrm{UO}_{2}$ are hard to detect using Transmission Electron Microscopy (TEM). Meanwhile, they do seem to account for the differences in EXAFS and TEM data (Gupta, 2015). The model thus provides the ability to better interpret EXAFS data by taking into consideration all classes of clusters down to the single atomic defects. However, concerning real irradiation experiments, which are either performed in reactor or by using $\mathrm{Xe}, \mathrm{Kr}$ or $\mathrm{He}$ ions, 

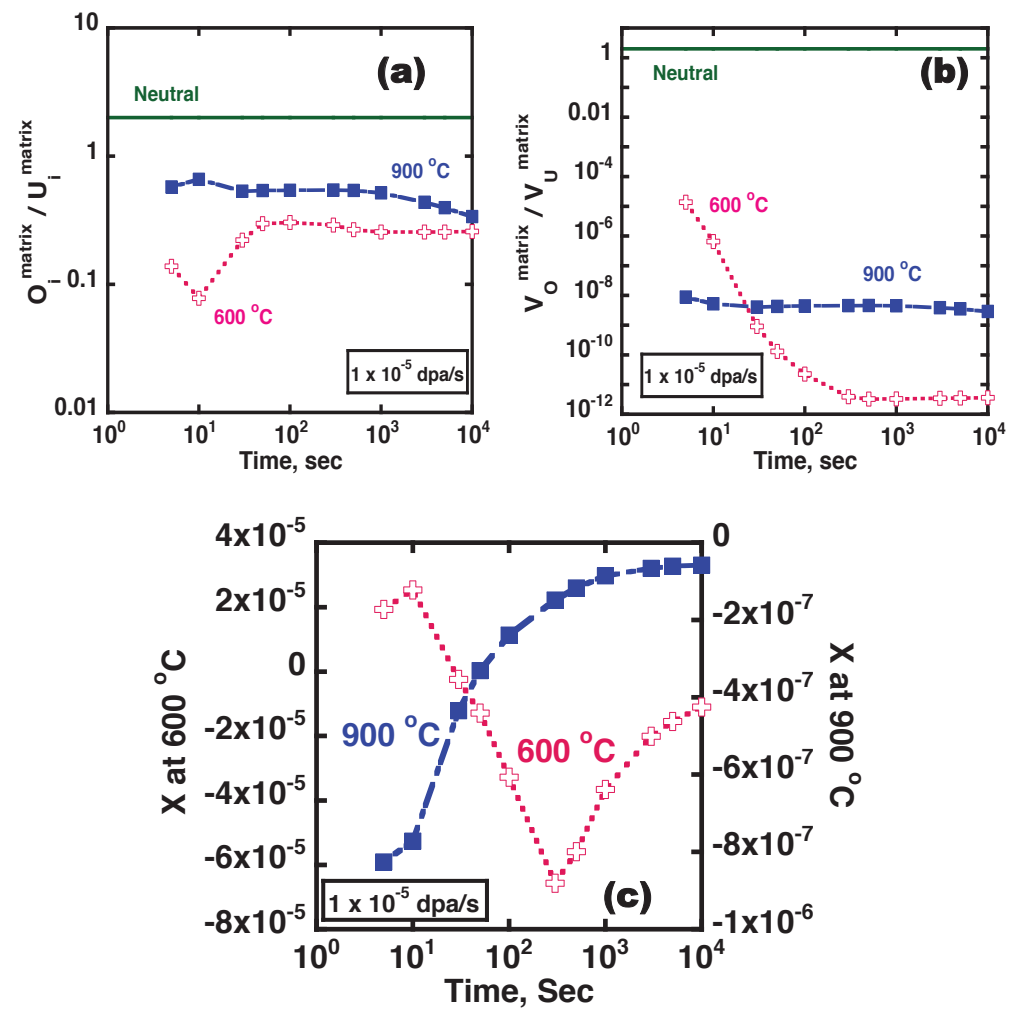

Figure 11: Evolution of (a) $\left(\mathrm{O}_{\mathrm{i}} / \mathrm{U}_{\mathrm{i}}\right)_{\text {Matrix }}$ and (b) $\left(\mathrm{V}_{\mathrm{O}} / \mathrm{V}_{\mathrm{U}}\right)_{\text {Matrix }}$ at $600{ }^{\circ} \mathrm{C}$ and $900{ }^{\circ} \mathrm{C}$ and dose rate of $1 \times 10^{-5} \mathrm{dpa} / \mathrm{s}$. (c) $\mathrm{Change}$ in the non-stoichiometry parameter $x$ at $600{ }^{\circ} \mathrm{C}$ and $900{ }^{\circ} \mathrm{C}$.

the predictive ability of this model will be highly improved once gaseous species generated in the reactor or introduced by ion irradiation are taken into consideration. The presence of gas atoms in the matrix is known to influence point defect clustering and gas bubbles, voids with gas atoms inside, tend to form when gas atoms are present. A future extension of the work to include gaseous species is thus critical for comparison with experiments.

\section{Summary and conclusions}

A non-stoichiometric cluster dynamics model was developed and applied to the formation of voids and loops in $\mathrm{UO}_{2}$ under irradiation. The model accounts for the fact that vacancy and interstitial clusters may contain a ratio of defects that differ from the $2: 1$ ratio dictated by the chemical formula of the ideal $\mathrm{UO}_{2}$ compound. The model thus tracks the density and composition of vacancy and interstitial clusters, as well as the off-stoichiometry of the matrix. The important results from the current model can be summarized as follows:

- Nucleation and growth of vacancy and interstitial clusters in $\mathrm{UO}_{2}$ are dominated by Frenkel defects as opposed to Schottky defects. Irradiation can thus cause off-stoichiometric evolution of this important material.

- The migration energy of $\mathrm{V}_{\mathrm{U}}$ is a limiting barrier for the growth of voids at lower temperature.

- The majority of voids and loops have non-stoichiometric compositions, with hypo-stoichiometry favored during earlier growth at lower temperatures and hyper-stoichiometry favored at later stages at higher temperatures. At temperatures above $600^{\circ} \mathrm{C}$ and an irradiation rate of $1 \times 10^{-5}$, the dominant composition of extended defects is hyper-stoichiometric.

- The $\mathrm{UO}_{2}$ matrix tends to become hyper-stoichiometric by irradiation due to the accumulation of $\mathrm{V}_{\mathrm{U}}$, which is connected with the relatively low mobility of $U$ vacancies. 
The finding that irradiation causes $\mathrm{UO}_{2}$ to become hyper-stoichiometric agrees with previously published works. However, this result adds to the existing controversy in the literature as to whether $\mathrm{O}$ interstitials or $\mathrm{U}$ vacancies are responsible for hyper-stoichiometry of $\mathrm{UO}_{2}$.

\section{Acknowledgements}

A.E. acknowledges support from Idaho National Laboratory under a subcontract titled Microstructure Evolution in $\mathrm{UO}_{2}$ at Purdue University. The authors wish to thank Rawan Mostafa for help with the calculation of the cluster composition space for dislocation loops.

Funding: This material is based upon work supported under an Integrated University Program Graduate Fellowship and the Center for Materials Science of Nuclear Fuel, an Energy Frontier Research Center funded by the U.S. Department of Energy, Office of Sciences, Office of Basic Energy Sciences under award number FWP 1356. 


\section{References}

L.-F. He, M. Gupta, C. A. Yablinsky, J. Gan, M. A. Kirk, X.-M. Bai, J. Pakarinen, T. R. Allen, In situ TEM observation of dislocation evolution in Kr-irradiated UO2 single crystal, Journal of Nuclear Materials 443 (2013) 71-7.

J. A. Turnbull, The Distribution of the Intragranular Fission Gas Bubbles in $\mathrm{UO}_{2}$ During Irradiation, Journal of Nuclear Materials 38 (1971) 203-12.

C. Baker, The Fission Gas Bubble Distribution in Uranium Dioxide From High Temperature Irradiated SGHWR Fuel Pins, Journal of Nuclear Materials 66 (1977) 283-91.

340 R. M. Cornell, M. V. Speight, B. C. Masters, The Role of Bubbles in Fission Gas Release From Uranium Dioxide, Journal of Nuclear Materials 30 (1969) 170-8.

R. M. Cornell, J. A. Turnbull, The Nucleation of Bubbles and Re-Solution Effects in Uranium Dioxide Irradiated at Elevated Temperatures, Journal of Nuclear Materials 41 (1971) 87-90.

K. Nogita, K. Une, Radiation-Induced Microstructural Change in High Burnup $\mathrm{UO}_{2}$ Fuel Pellets, Nuclear Instruments and Methods in Physics Research Section B: Beam Interactions with Materials and Atoms 91 (1994) 301-6.

J. Jonnet, A Contribution to the Understanding of the High Burn-up Structure Formation in Nucleat Fuels, PhD Dissertation, European Commission, Institute for Transuranium Elements, unit: Materials Research

B. Ye, Formation And Growth Of Irradiation-Induced Defect Structures In Ceria, PhD Dissertation, University of Illinois at Urbana-Champaign .

N. M. Ghoniem, H. Gurol, An Analytical Approach to Void Growth in Metals Under Intense Radiation Pulsing, Radiation Effects 55 (1981) 209-22.

R. H. Ning, Y. G. Li, W. H. Zhou, Z. Zeng, An improved cluster dynamics model for hydrogen retention in Tungsten, International Journal of Modern Physics C 23 (6) (2012) 1250042.

F. Christien, A. Barbu, Cluster Dynamics modelling of irradiation growth of zirconium single crystals, Journal of Nuclear Materials 393 (2009) $153-61$.

355 A. Gokhman, F. Bergner, Cluster dynamics simulation of point defect clusters in neutron irradiated pure iron, Radiation Effects and Defects in Solids 165 (3) (2009) 216-26.

N. M. Ghoniem, S. Sharafat, A Numerical Solution to the Fokker-Planck Equation Describing the Evolution of the Interstitial Loop Microstructure During Irradiation, Journal of Nuclear Materials 92 (1980) 121-35.

R. Skorek, S. Maillard, A. Michel, G. Carlot, E. Gilabert, T. Jourdan, Modelling Fission Gas Bubble Distribution in UO 2 , Defect and Diffusion Forum 323-325 (2012) 209-14.

H. Matzke, Atomic Transport Properties and Mixed Oxides (U, Pu)O ${ }_{2}$, Journal of Chemical Society, Faraday Transactions 2 83 (1987) $1121-42$.

A.-R. Hassan, A. El-Azab, C. Yablinsky, T. Allen, Defect disorder in $\mathrm{UO}_{2}$, Journal of Solid State Chemistry 204 (2013) 136145.

M. Lyons, R. Boyle, J. Davies, V. Hazel, , T. Rowland, UO 2 Properties Affecting Performance, Nuclear Engineering and Design 21 (1972) 167-99.

M. Gupta, Radiation Damage on Multiple Length Scales in Uranium Dioxide, Ph.D. thesis, University of Wisconsin-Madison, 2015.

365 F. A. Kröger, H. J. Vink, Relations between the Concentrations of Imperfections in Crystalline Solids, Solid State Physics 19 (1956) 307-435.

A. Hindmarsh, Large Ordinary Differential Equation Systems and Software, Control Systems Magazine, IEEE 2 (4).

L. Petzold, Automatic Selection of Methods for Solving Stiff and Nonstiff Systems of Ordinary differential equations, SIAM Journal on Scientific and Statistical Computing 4 (1) (1983) 136-48.

S. Khalil, Multiscale Modeling of Nucleation and Growht of Defect Clusters in $\mathrm{UO}_{2}$, Ph.D. thesis, University of Wisconsin-Madison, 2014.

370 Y. Miao, D. Aidhy, W.-Y. Chen, A. O. Kun Mo, D. Wolf, J. F. Stubbins, The evolution mechanism of the dislocation loops in irradiated lanthanum doped cerium oxide, Journal of Nuclear Materials 445 (1-3) (2014) 209-17.

G. Martin, P. Garcia, C. Sabathier, L. V. Brutzel, B. Dorado, F. Garrido, S. Maillard, Irradiation-induced heterogeneous nucleation in uranium dioxide, Physics Letters A 374 (30) (2010) 3038-41.

Y. G. Li, W. H. Zhou, R. H. Ning, L. F. Huang, Z. Zeng, X. Ju, A Cluster Dynamics Model For Accumulation of Helium in Tungsten Under Helium Ions and Neutron Irradiation, Commun. Comput. Phys. 11 (5) (2012) 1547-68.

A. H. Duparc, C. Moingeon, N. S. de Grande, A.Barbu, Microstructure modelling of ferritic alloys under high flux $1 \mathrm{MeV}$ electron irradiations, Journal of Nuclear Materials 302 (2002) 143-55.

A. Barbu, E. Clouet, Cluster Dynamics Modeling of Materials:Advantages and Limitations, Solid State Phenom. 129 (2007) 51-8.

D. L. Deforest, Transient fission gas behavior in uranium nitride fuel under proposed space applications, AIR FORCE INST OF TECH WRIGHTPATTERSON AFB OH AFIT/CI/CIA-92-001D.

X. M. B. et al., Migration mechanisms of oxygen interstitial clusters in $\mathrm{UO}_{2}$, J. Phys.: Condensed Matter 25 (015003).

M. Iwasawa, Y. Chen, Y. Kaneta, T. Ohnuma, H.-Y. Geng, M. Kinoshita, First-Principles Calculation of Point Defects in Uranium Dioxide, Materials transactions 47 (11) (2006) 2651-7.

Y. Yun, P. M. Oppeneer, H. Kim, K. Park, Defect energetics and Xe diffusion in $\mathrm{UO}_{2}$ and $\mathrm{ThO}_{2}$, Acta Materialia 57 (5) (2009) $1655-9$.

385 Q. Xu, N. Yoshida, T. Yoshiie, Accumulation of Helium in Tungsten Irradiated by Helium and Neutrons, Journal of Nuclear Materials $367-370$ (2007) 806-11. 